
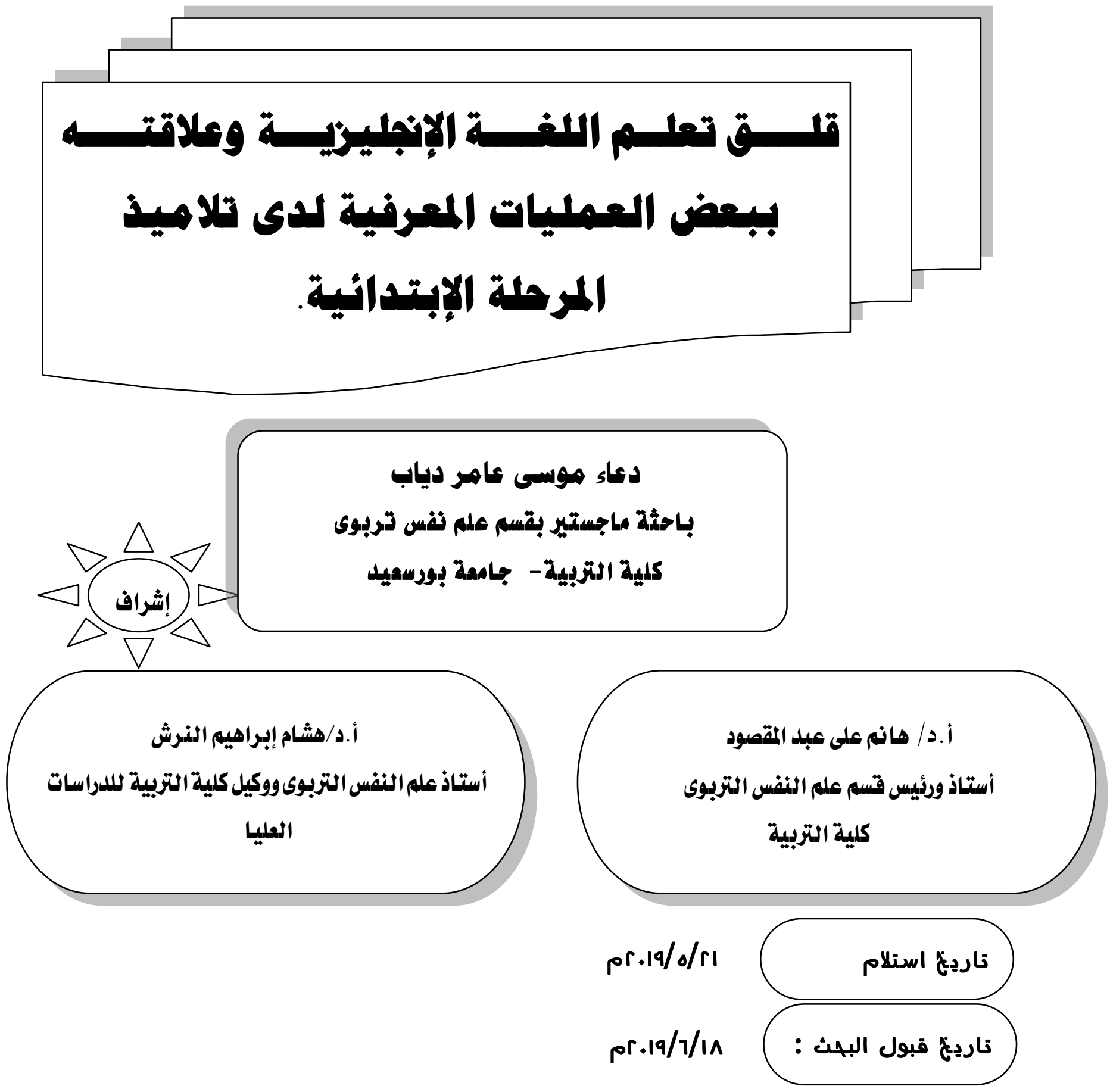


\section{مستخلص الرسالة:}

تهلف الدراسة إلى التعرف على العلاقة بين قلق تعلم اللغة الإنجليزية ويعض العمليات المعرفية لدى

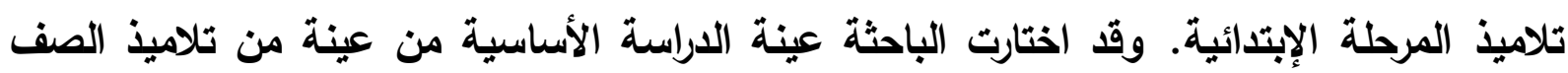

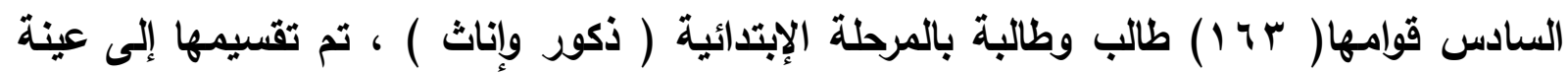

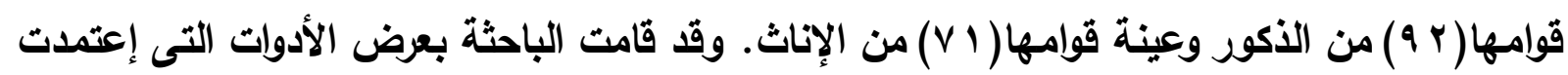

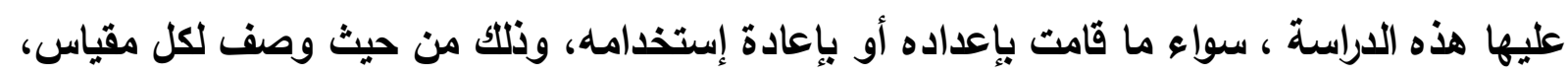

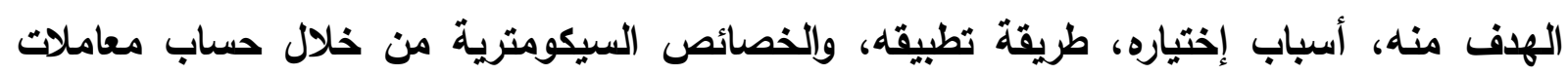

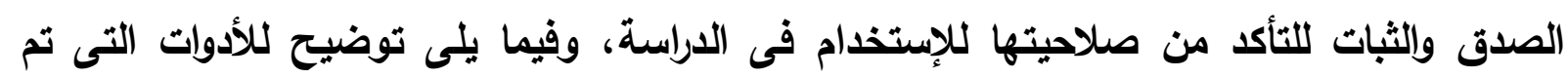

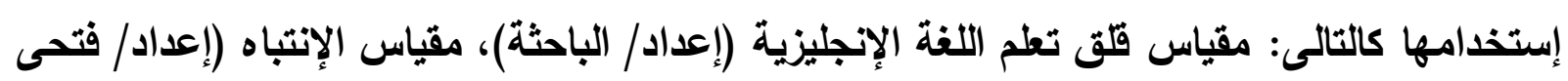

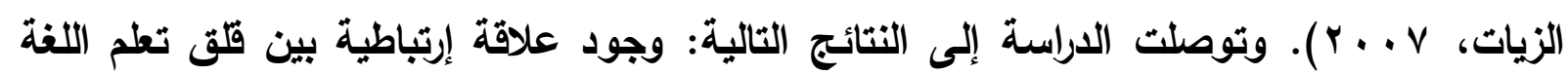
الإنجليزية والإنتباه لدى تلاميذ المرحلة الإبتدائية، عدم وجود فروق الفئ دالة إحصائياً بين الذكور والإناث

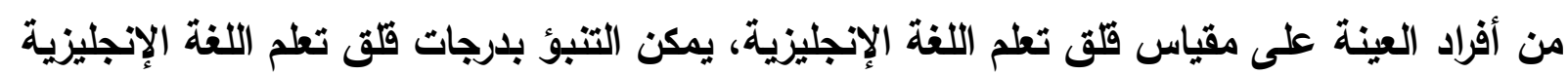
لاى تلاميذ المرحلة الإبتدائية من درجاتهم فى مقياس الإنتباه. الكلمات المفتاحية: قلق تعلم اللفة الإنجليزية، العمليات المعرفية، الإنتباه. 
The study aims to identify the relation between English language learning anxiety and some of the cognitive processes among students in primary schools . The researcher selected the main sample of the study that include(163students) in primary schools (92 male, 71 female).The researcher presented the tools on which this study was based, Whether it is prepared or reused, In terms of description of each scale, Its target, reasons for selection, how to apply it, and cycometric properties through the calculation of coefficients of validity and reliability to ensure its validity for use in the study, The following are the tools that have been used as follows: The scale of English language learning anxiety (prepared by the researcher), The scale of attention (prepared by Fathy Alzayat, 2007). The study found the following results: There is a correlation between English language learning anxiety and attention among students in primary schools, There were no statistically significant differences among males and females of the sample members on the scale of English language learning anxiety students level of English language learning anxiety can be predicted by using their scores in attention

scale.

Keywords: English language learning anxiety, Cognitive processes, Attention. 
اهتم علماء علم النفس التريوى بموضوع القلق، كأحد المتغيرات الرئيسية فى التربية، ونظرا لأنه يرتبط بطبيعة الموقف أو الخبرة التى يمر بها الفرد فقد كان للقثق فى المجال التربوى عدة أنماط، مثل: قلق الإختبار Test Anxiety، قلق التحصيل Achievement Anxiety، قلق الأداء Learning Permance Anxiety . كما تبين أن الأفراد القلقين بلرجة كبيرة يعطون نتائج ضعيفة عند الإجابة على الأسئلة Anxiety

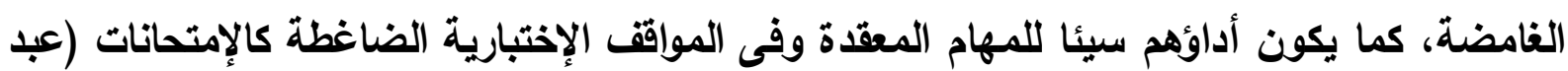

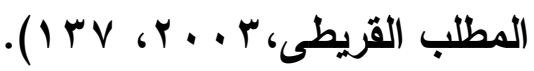

ولعل النظرية الأكثر شيوعا هى نظرية سبيلبيرجر حيث عرف قلق ت تطلم اللغة

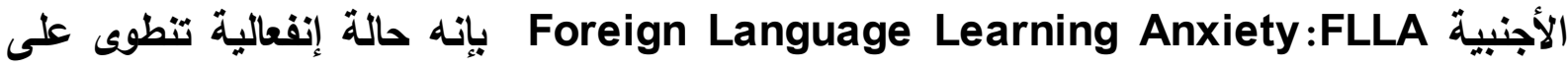
جملة من مشاعر التوتر، والعصبية لإرتباطه بالجهاز العصبى. ويالتالى قسم القلق إلى ثلاث مكونات

Personal Anxiety - قلق السمة وهى سمة الشخصية.

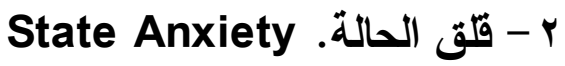
r- قلق خاص بالموقق. Situation Specific Anxiety (piniel,2006,40). ويمكن تحديد مستوى قلق تعلم اللغة الإنجليزية عند تلميذ المرحلة الإبتدائية من خلال الدرجة

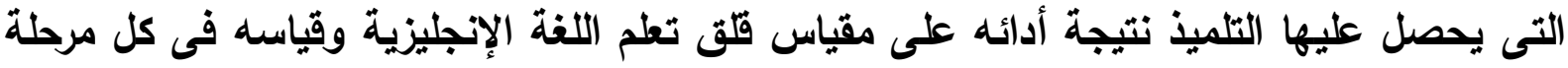

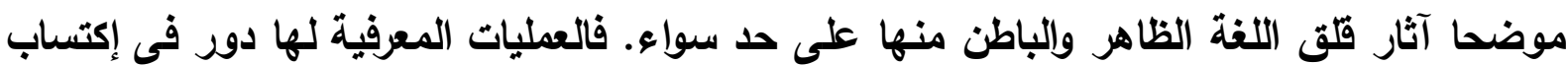
اللغة وذلك من خلال نموذج التطم المكون من ثلاث مراحل هى: Input . المدخلات من جسات

Processing العمليات

(Peter and Gadner, 1994,283) Output . المخرجات هناك العايد من الطلاب الذين يعانون من قلق تعلم اللغة فى الفصول الدراسية Classroom English Language Anxiety

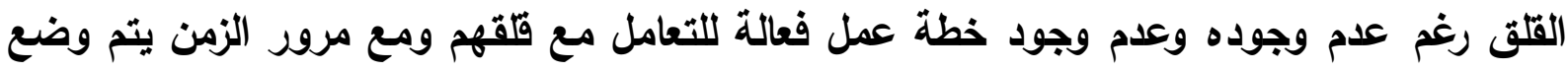
التوقعات الإيجابية لسلوكياتهز فى المواقف التطليمية ويصبح التواصل جزئا منتظما من من العملية (Dayhoff,2000,15) التعليمية.

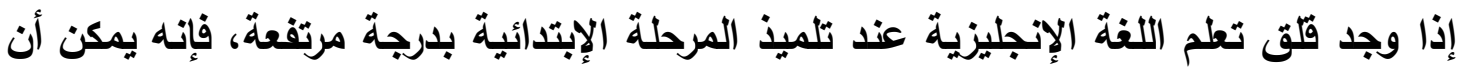

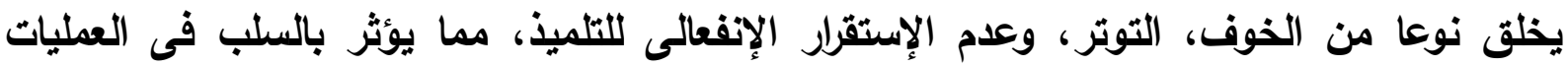

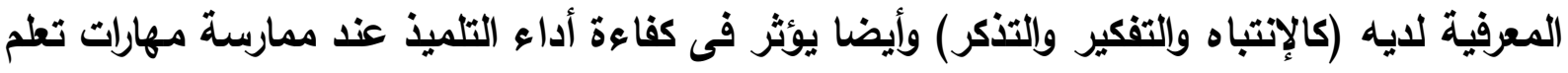




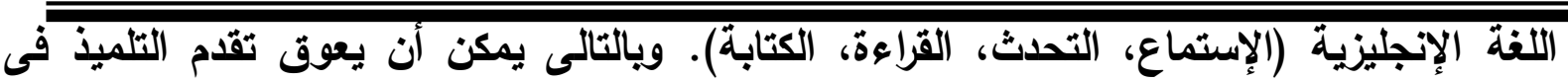
التحصيل الدراسى لمادة اللغة الإنجليزية، ليس فقط فى هذه المرحلة، بل يمكن أن يمتد للمراحل

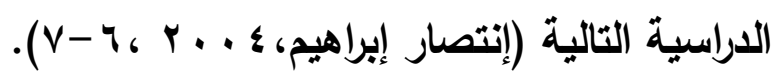

ولخفض قلث التعلم داخل الفصول الدراسية لابد من مواجهة الظروف التى تهاد بيئة تطلم اللغة ،لئة

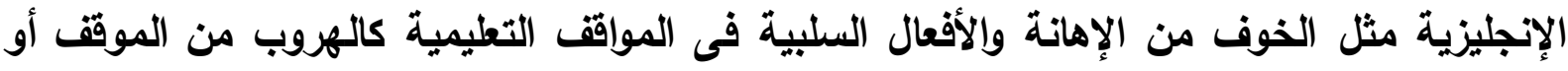
الغياب من الإمتحان وكلها وسائل تكيف دفاعية عصبية بهدف الإفاع عن الألاتهات أمام هذا التهديد (Dornyei, 2001,91) ، ويالتالى ظهرت الحاجة لإكتشاف ركيزة أساسية لإكتساب اللغة الإنجليزية

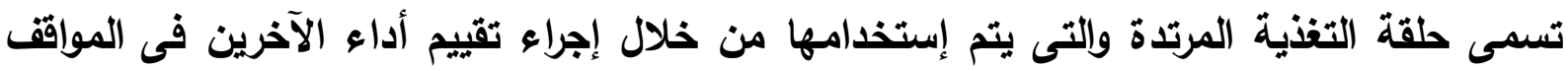
المختلفة وتطم الطلاب بثكل أكثر إستفادة من خلال إنعكاس خبراتهم التعليمية على تعلمهم وتلقى إلى

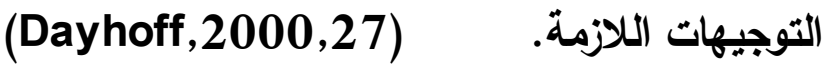
ويلاحظ أن مستوى القلق عندما يكون معدوما أو منخفضا يؤدى إلى تثبيط الأداء وضعفه حيث لا تتوافر الطاقة الدافعية بالقدر اللازم، وعندما يبلغ مستوى القلق حدا معتدلان- فإنه يعد دافعا للأداء

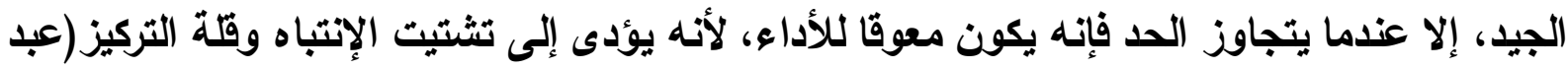

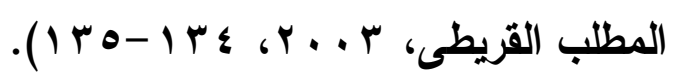

وقد اهتم علماء النفس بالإنتباه بإعتباره من أهم العمليات العقلية التى تلعب دوراً هامأً فى

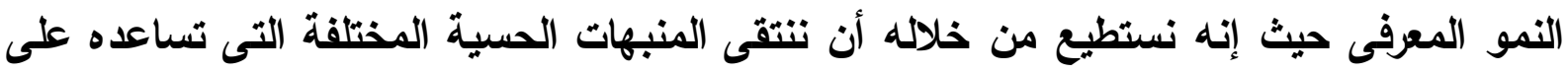

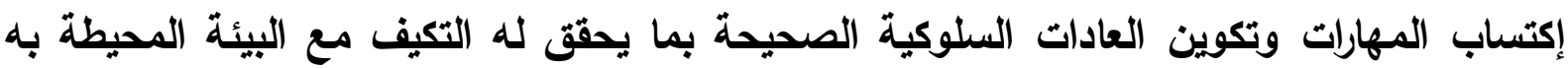

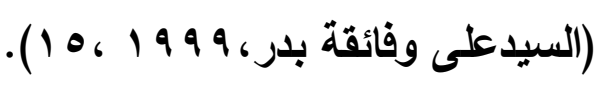

حيث يلعب الشعور بالتهديد دورا هاما فى ظهور القلق، لأن التهايد يؤدى إلى انحراف الإنتباه.

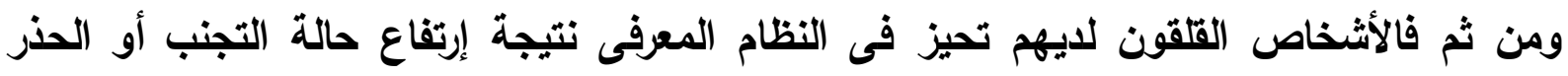

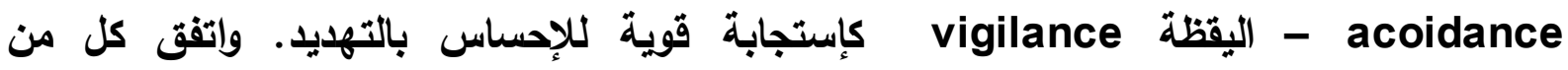
Bradley (1998,737-753) Mogg (1993,304-311) الثخص القلق بواسطة مثير التهديد، وقد يؤدى إلى تثبيت مثيرات التهديد، ويكون توجه الأفراد

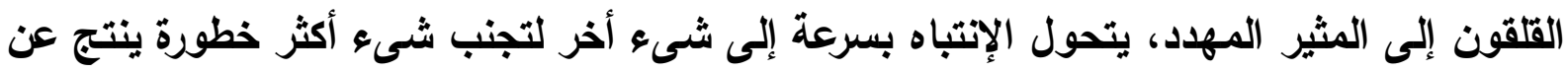

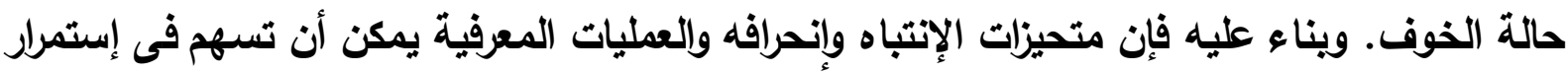
القلقى.

ويزداد مدى الإنتباه ومدته وحدته إذا كاتت موضوعات الإنتباه منظمة تنظيما خاصا، وكثيرا ما

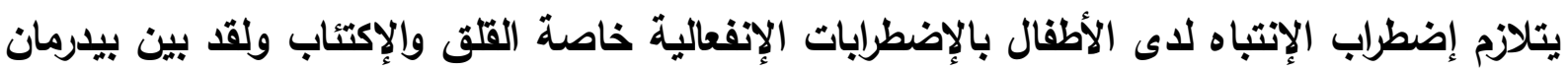

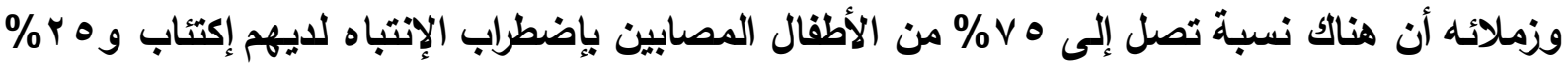

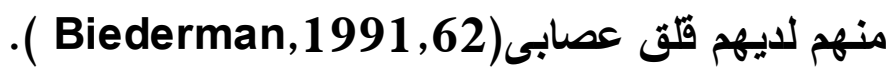




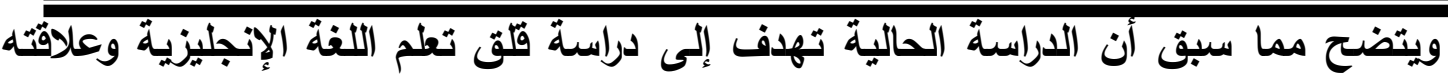

بالإنتباه لاى تلاميذ المرحلة الإبتدائية حتى يمكن الوصول بمستوى القلق إلى مستوى مناسب لضمان تعلم أفضل والمساعدة فى إثراء عملية تعلم اللغة الإنجليزية.

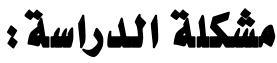

لاثك أن الطلاب يتباينون فيما بينهم فى مستويات القلق؛ حيث يبدو القلق عند البعض فى ظهور حالات من الخوف العام من المدرسة ككل، بينما البعض الآخر من الزملاء أو مادة من المواد

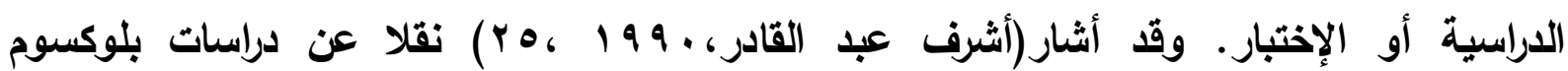
Blouksoum، وأندرسون Anderson، أن تحصيل التلاميذ ذوى القلق المتوسط أفضل من تحصيل التلاميذ ذوى القلق المرتفع والمنخفض. وتوصل ماتاترازو matarazzo إلى أن متوسط درجات المجموعة ذات القلق المنخفض أعلى من متوسط درجات مجموعة القلق العالى(محمد عبد

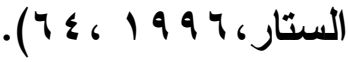

ويعد قلق تعلم اللغة الإنجليزية من المشكلات التى يجب البحث عن حلول لها والتظلب عليها، حيث إنه لا يستطيع التلاميذ تحقيق المستوى المتوقع بالمقارنة بقراتهم العقلية ودرجة ذكائهم، من خلال ذلك تتلخص مشكلة الاراسة الحالية فى التعرف على تأثير قلق تعلم اللغة الإنجليزية وعلاقته بالعمليات المعرفية لدى الجنسين من تلاميذ المرحلة الإبتدائية. ويمكن صياغة مشكلة الدراسة الحالية فى الأسئلة التالية:

1 - هل توجد علاقة إرتباطية بين قلق تعلم اللغة الإنجليزية والإنتباه لدى تلاميذ المرحلة الإبتدائية؟ ץ - هل توجد فروق دالة إحصائيا بين الأكور والإناث من تلاميذ المرحلة الإبتدائية فى درجات قلى تعلم اللغة الإنجليزية؟ ץ- هل يمكن التببؤ بلرجات قلق تعلم اللغة الإنجليزية لاى تلاميذ المرحلة الإبتدائية من درجاتهم فى مقياس الإنتباه ؟

أهداف الداسراسة: ا - معرفة العلاقة بين قلث تعلم اللغة الإنجليزية ويعض العمليات المعرفية لاى تلاميذ المرحلة الإبتدائية. ץ - معرفة أثز النوع على قلق تعلم اللغة الإنجليزية لاى تلاميذ المرحلة الإبتدائية. ب - التتبؤ بلرجات قلق تعلم اللغة الإنجليزية لاى تلاميذ المرحلة الإبتدائية من درجاتهم فى مقياس الإنتباه - إن 
أهمية اللدراسة ؛

1 - تسهم هذه الاراسة فى زيادة فهمنا لطبيعة القلق، والوصول إلى معدل مناسب يعمل على تحسين عملية تطم اللغة الإنجليزية والتخلص من التلق فئل المعوق.

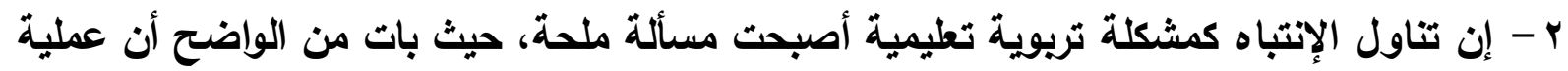

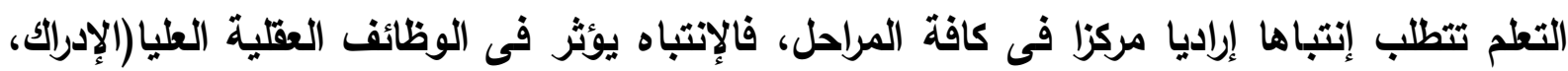

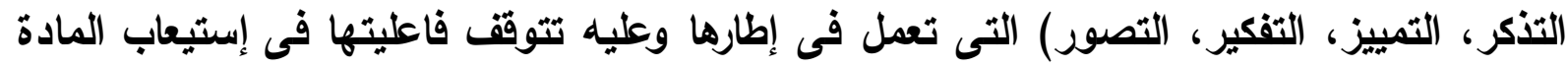
التطليمية والإحتفاظ بها وإسترجاعها. r- توجيه نظر المطين إلى أهمية إستخدام إستراتيجيات التعلم من خلال اللعب والأغانى لتنمية القدرات المعرفية للطلاب. ع - توجيه المطمين وتبصيرهم بأهمية إستثارة دافعية الطلاب لتعلم اللغة الإنجليزية، وذلك عن طريق

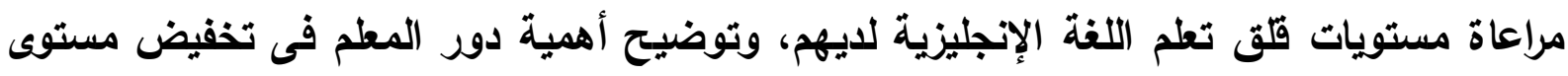
القلق لاى الطلاب.

\section{منهج الدراسة :}

إعتمدت الدراسة الحالية على المنهج الوصفى بإعتبار أن للبحوث الوصفية أهمية متميزة فى الهى

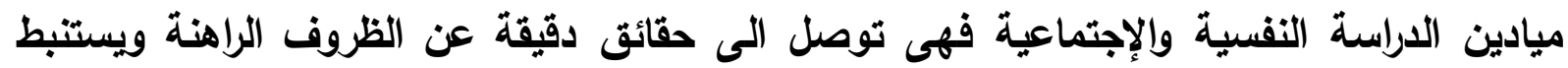
العلاقات الهامة القائمة يين الظواهر المختلفة، وتفسر معنى البيانات، وتمد الباحثين بمعلومات دقيقة

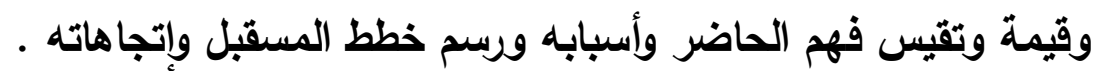
عينة الدراسة:

قامت الباحثة بإختيار العينة من تلاميذ المرحلة الإبتدائية ذوى قلق تعلم اللغة الإنجليزية والذين تم تحديدهم وفقا لارجاتهم فى مقياس قلق تطم اللغة الإنجليزية نظراً لأن معظم الدراسات

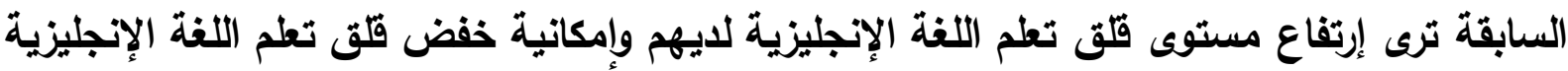
فى مرحلة مبكرة تكون أفضل.

وتم إختيار العينة من مدرستين إحداهما حكومية والآخرى خاصة بمحافظة بورسعيد للعام

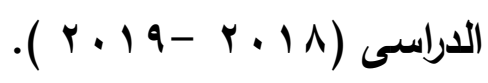

تكونت عينة الاراسة الأساسية من عينة من تلاميذ الصف السادس قوامها ( ب 1 ( ) طالب وطالبة بالمرحلة الإبتدائية ( ذكور وإناث ) ، تم تقسيمها إلى عينة قوامها (ب 9 ) من الذكور وعينة

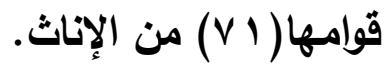




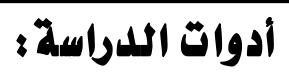

قامت الباحثة بعرض الأدوات التى إعتمدت عليها هذه الدراسة ، سواء ما قامت بإعداده أو ما قامت بإعاده إستخدامه، وذلك من حيث وصف لكل مقياس، الهدف منه، أسباب إختياره فى الدراسة الحالية، طريقة تطبيقه، والخصائص السيكومترية من خلال حساب معاملات الصدق والثبات للتأكد من صلاحيتها للإستخدام فى الاراسة الحالية، وفيما يلى توضيح للأدوات التى تم إستخدامها كالتالى:

$$
\text { r - مقياس قلثى تعلم اللغة الإنجليزية. إعداد / الباحثة }
$$

فروض اللدراسة:

من خلال إطلاع الباحثة على الإطار النظرى ولاراسات السابقة بمكن صباغة فروض الاراسة الحالبة كما بلإنى:

1 - توجد علاقة إرتباطية بين قلق تعلم اللغة الإنجليزية والإنتباه لدى تلاميذ المرحلة الإبتدائية.

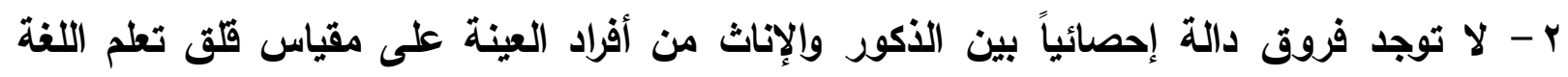
الإنجليزية. r- يمكن التتبؤ بلرجات قلق تعلم اللغة الإنجليزية لاى تلاميذ المرحلة الإبتدائية من درجاتهم فى مقياس الإنتباه. إتبعت الباحثة الخطوات التالية لإختبار صحة فروض الإراسة من خلال :

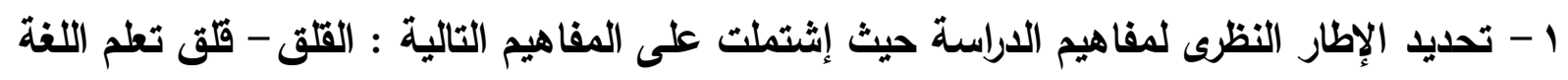

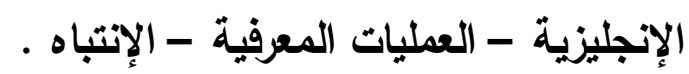
r - إستعراض الاراسات والبحوث السابقة (عربية، أجنبية) .

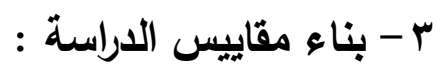
أ - بناء مقياس قلث تطم اللغة الانجليزية .

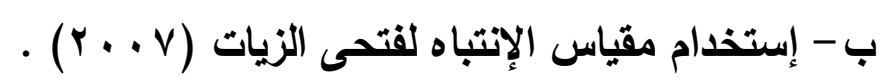
ع - ضبط المقاييس من خلال : أ - عرض المقاييس على مجموعة من المحكمين لإبداء الرأى .

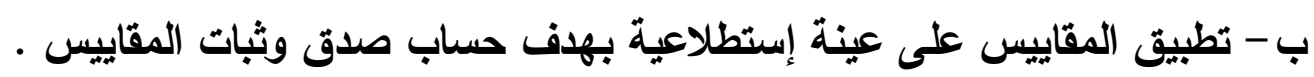

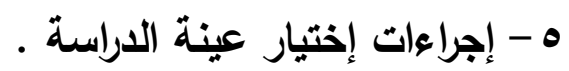
צ - تطبيق أدوات الاراسة على العينة النهائية .

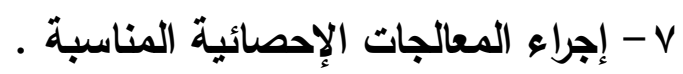




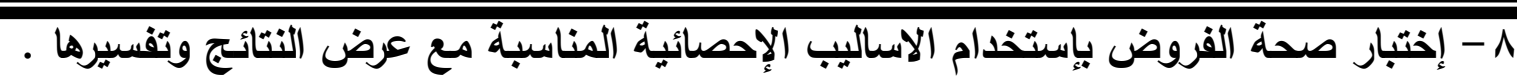
9 - صياغة مجموعة من التوصيات والمقترحات فى ضوء نتائج الاراسة .

نتائج الدراسة ومناقشتهـا أولاء إختبار صحة الفرض الأول :

لإختبار صحة الفرض الأول والذى ينص على إنه "توجد علاقة إرتباطية بين قلق تعلم اللغة

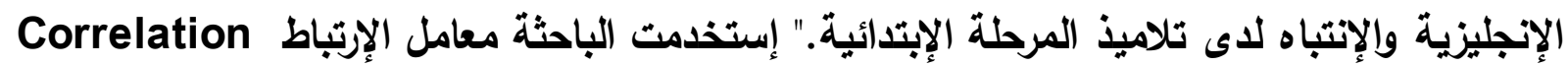

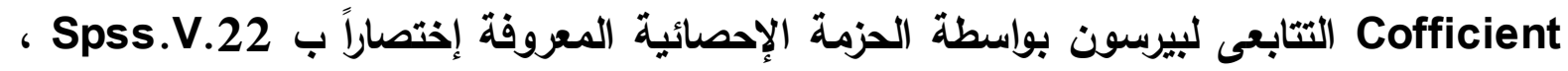
ويوضح الجدول التالى نتائج هذا الفرض:

جدول (1)

قيمة معامل الإرتباط بين قلق تعلم اللغة الإنجليزية والإنتباه

ومستوى دلالته (ن= ب r 1 )

\begin{tabular}{|c|c|c|}
\hline مستوى الدلالة & قيمة معامل الإرتباط & المتغيرات \\
\hline$\ldots 1$ &..$T V Y$ & الإتتباه تعلم اللغة الإنجليزية \\
\hline
\end{tabular}

مما سبق يتضح صحة الفرض الأول، حيث تتقق نتائج هذا الفرض مع نتائج الدراسات

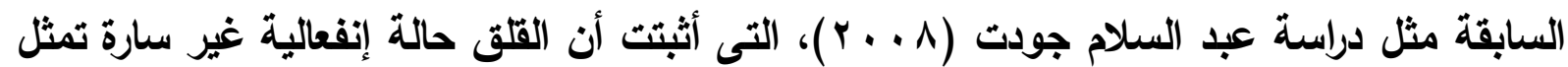
مزيجا من مشاعر الخوف المستمر مصحويا بمتفبرات فسيولوجية وتدهور القدرة على التفكير وصعوية

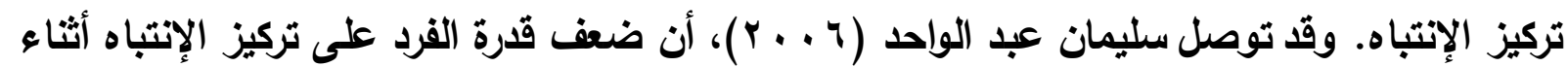
التعم هو إضطراب نقص الإنتباه الذى من مظاهره القلق، والإضطراب، والتوتز، وقصر فترة الإنتباه

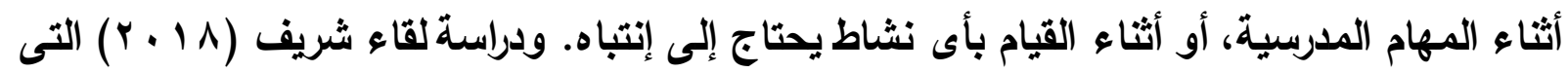
تناولت الإنتباه التتفيذى وعلاقته بالثخصية القلقة لاى طلبة المرحلة الإعدادية وأن زيادة القلق لدى

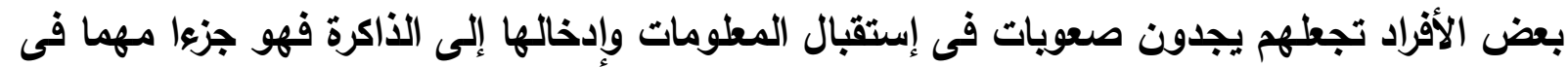

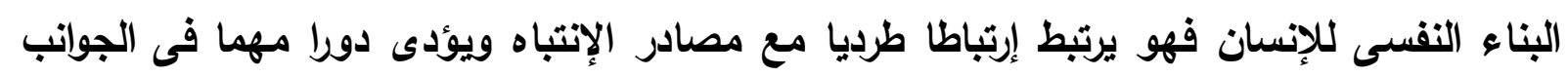

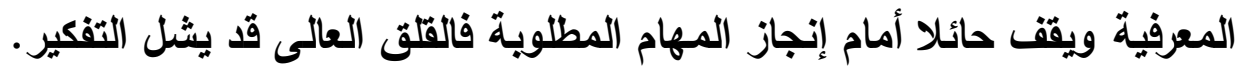
ومن جهة أخرى يمكن تفسير النتائج فى ضوء الإطار النظرى والدراسات السابقة، حيث أثنتئ

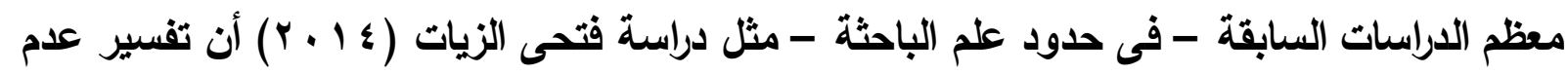

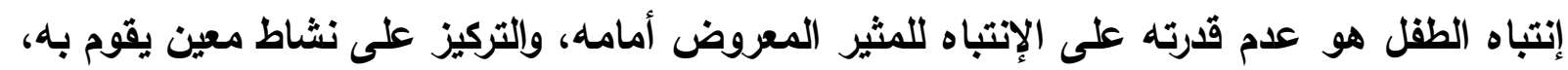
حيث تنجح المثيرات الخارجية فى جذب إنتباهه بعيدا عن هذا النشاط وعدم قدرته على إكمال العمل 


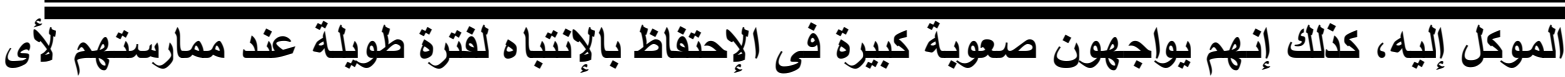

نشاط، ويصفة خاصة تلك الأنشطة التى تتكرر كثيرا، أو التى يجدون صعوية فى غربلة المثيرات. وقد وجدت الباحثة أن العديد من الدراسات العربية والأجنبية إتفقت معها، مثل كندال

Kandall الإنتباه. ولذا يعد الإنتباه من أهم العمليات العقلية التى تؤدى دورا مؤثرا فى النمو المعرفى لادى الفرد إذ يساعده على الإتيان بالسلوكيات الإيجابية المرغوب فيها ليحقق التوافق مع المحيط الأى يعيش فيه، لألك القلق يحول دون تعلم السلوكيات الإيجابية ويحدث الإنفصال عن العالم المحيظ به. أما الدراسة العربية هى دراسة فتحى الزيات ( 9 ( 9 ( )، التى أثبتت أن نظرية العجز أو القصور الإستثارى تفسر ضعف القلق لاى بعض الطلاب إلى أن نظام الإستثارة (Theory arousat -deficit) البيولوجى أو ما يمكن أن يطلق عليه نظام أو جهاز اليقظة لا يعمل على نحو ملائم لاى هؤلاء،

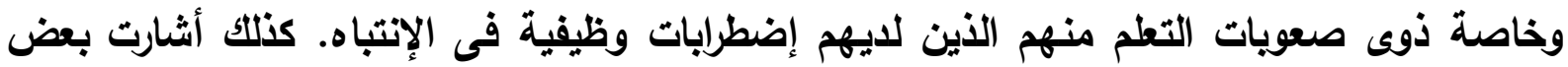
الاراسات إلى أن العوامل النفسية مثل القلق والإحباط يساعد فى إظهار أعراض إضطراب نقص الإنتباه

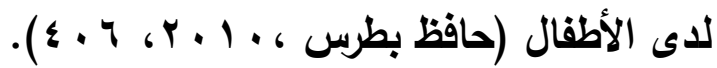
يتضـ من الجدول السابق وجود علاقة إرتباطية موجبة دالة إحصائياً عند مستوى ا ... بين

قلق تعلم اللغة الإنجليزية والإنتباه.

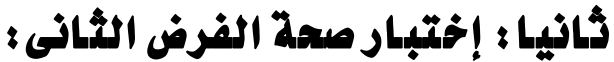

لإختبار صحة الفرض الثانى والأى ينص على إنه "لا توجد فروق دالة إحصائيا بين الذكور والإناث

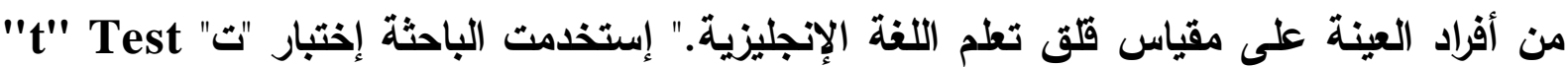
SpsS للمجموعات المستقلة غير المتساوية العدد بواسطة الحزمة الإحصائية المعروفة إختصاراً بهن V.22 ، ويوضح جدول (Y) نتائج هذا الفرض:

جدول (r)

المتوسطات والإنحرافات المعيارية وقيمة "ت "

ومستوى دلالتها للأكور والإناث على مقياس قلث تعلم اللغة الإنجليزية

\begin{tabular}{|c|c|c|c|c|c|c|c|c|}
\hline \multirow{3}{*}{ الدلالة } & \multirow{3}{*}{ " قيمة " } & \multicolumn{6}{|r|}{ النوع } & الكعينة \\
\hline & & \multicolumn{3}{|r|}{ إناث } & \multicolumn{3}{|r|}{ ذكور } & \multirow{2}{*}{ المتغير } \\
\hline & & الإنحراف & المتوسط & العدد & الإنحراف & المتوسط & العدد & \\
\hline غير دالة &..$\wedge \wedge$ & YY.\& & 10r.s & vi & Yr.q & 104.0 & $9 r$ & الإنجليزية تلم \\
\hline
\end{tabular}




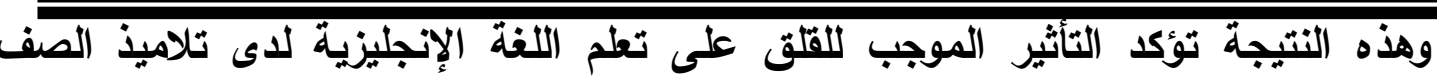

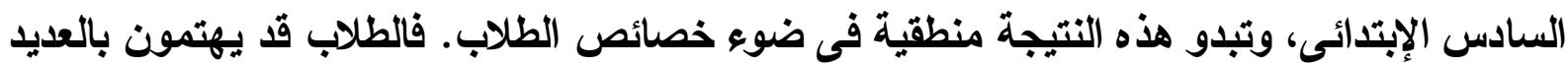

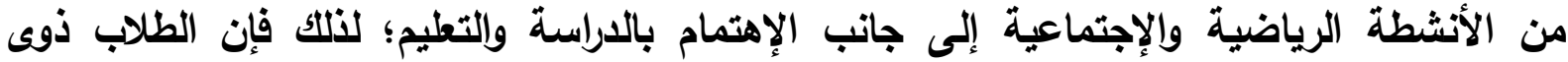
مستوى قلث التعم المرتفع تزداد دافعيتهم للتطم ويالتالى يبذلون جهدا أكبر فيه مما ينعكس إيجابيا

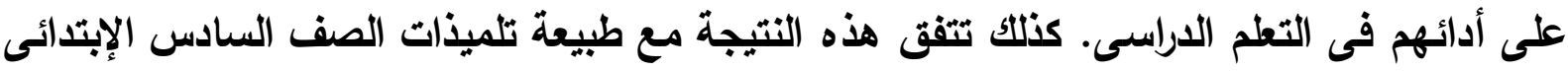
وظروفهن الإجتماعية التى تختلف تماما عن التلاميذ؛ فالمجهود الكبير الذى يبذل من قبل التلميذات

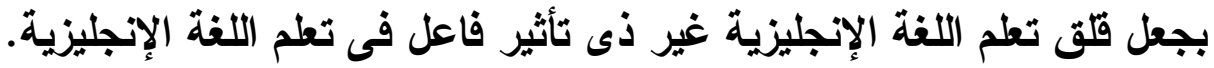

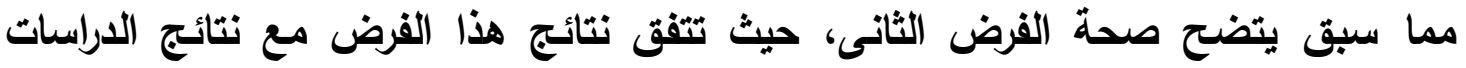
السابقة التى أثبتت علدم تأثير متغير النوع على التلاميذ فى فلق تعلم اللغة الإنجليزية، فلم تبين نتائج

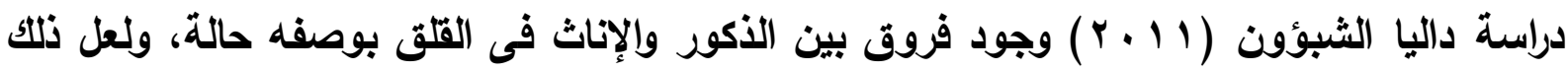

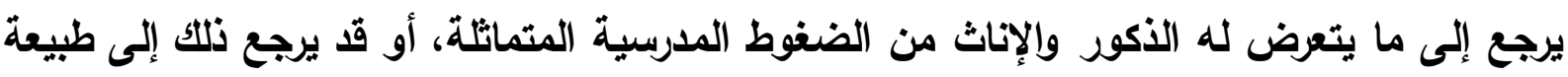

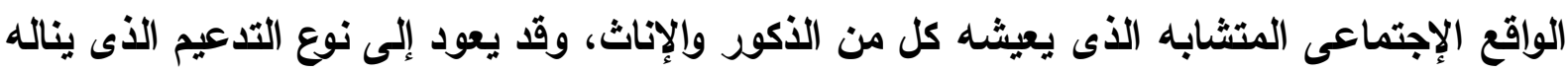

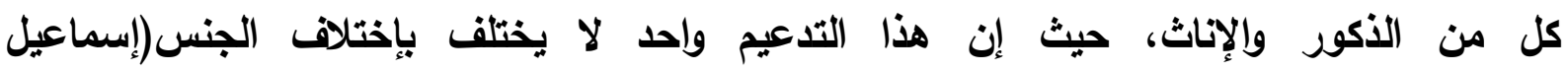

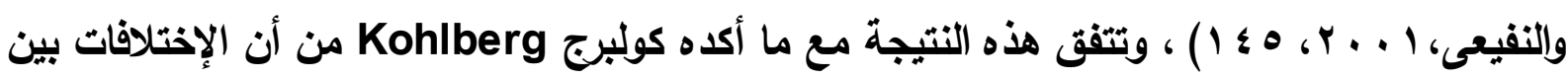

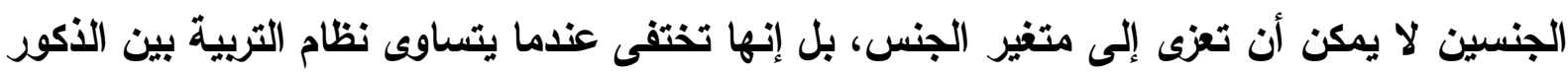

والإناث (Sprint et,1994,p.195).

بينما بينت نتائج الدراسة وجود فروق بين الأكور والإناث فى القلق بوصفه سمة وذلتك لصالح

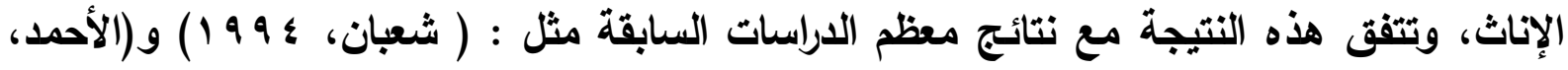

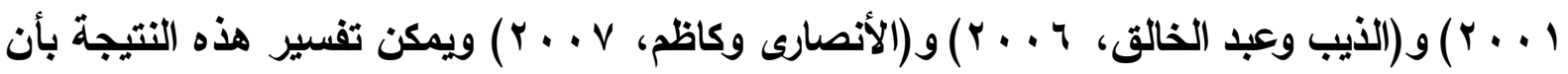
الإناث أكثر قلقا ؛ لأن طبيعة الأنثى تختلف عن طبيعة الذكر، بالإضافة إلى إختلاف أساليب التشئئة

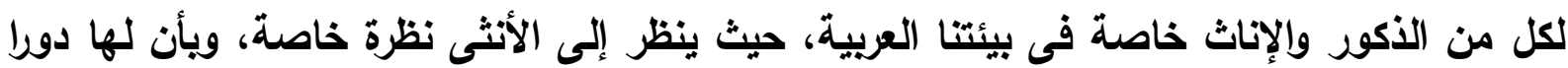

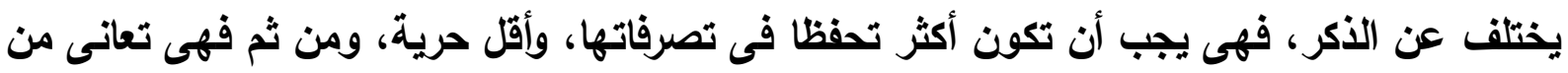

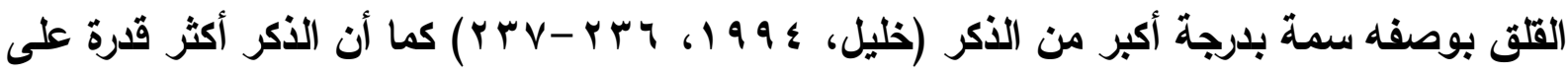

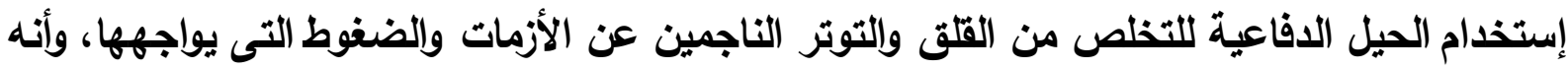

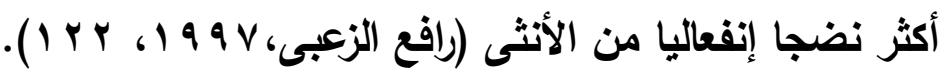

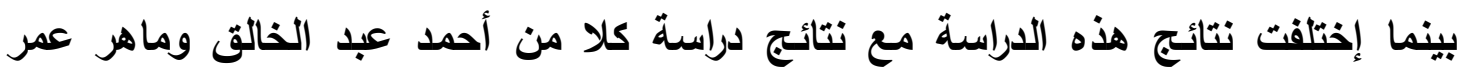

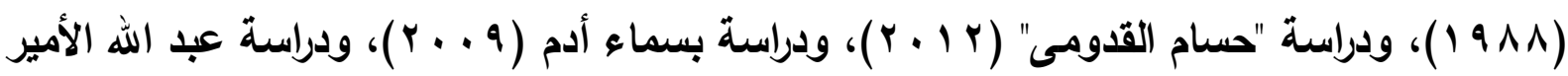

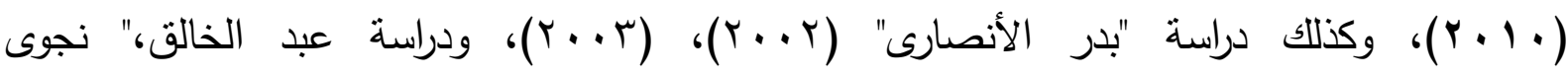

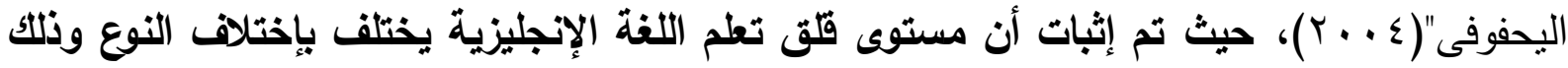

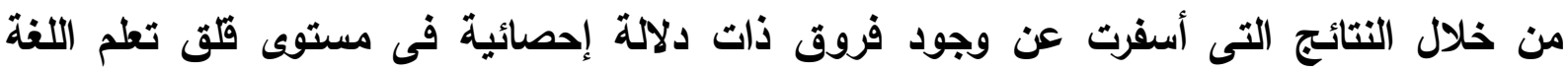


الإنجليزية بين الطلاب حيث حصلت الطالبات على متوبط أعلى من الطلاب فى القلى، وفى دراسية سارجيل Sarigul (2000) لقياس قلق تعلم اللغة الإنجليزية وجد إختلاف فى قلق تعلم اللغة بين الطلاب الأكور والإناث حيث أن المتعلمين الإناث لايهم مستويات مرتفعة من القثق أكثر من أقرانهم الذكور

ويمكن تفسير النتائج فى ضوء الإطار النظرى والدراسات السابقة، حيث أثبتت معظم الدراسات السابقة - فى حدود علم الباحثة - وجود فروق ذات دلالة إحصائية بين البنين والبنات بمقياس قلث تعلم اللغة الإنجليزية فى جميع المراحل التعليمية بصفة عامة والمرحلة الإبتدائية بصفة خاصة، مما يدل على أن خصائص المرحلة الإبتدائية لها دور كبير فى ذلك، فكل مرحلة لها مجموعة خصائص تميزها، وبالطبع هناك بعض البنين والبنات بهذه المرحلة يشتركوا فى الصفات أو الخصائص، وذلك يختلف فى المراحل العمرية المتقدمة، حيث توجد سمات مختلفة بين البنين والبنات تميزهم فيما بينهم وعن غيرهم

وقد وجدت الباحثة أن العديد من الدراسات العربية والأجنبية إتفقت معها، فقد أجريت عدد من الدراسات على الطلبة الجامعيين فى الولايات المتحدة وأثشارت إلى أن هناك علاقة موجبة بين التعرض للضغوط النفسية والإكتئاب والقلق، وأن مستوى الأعراض كان لاى الإناث أعلى منه لدى (الذكور.(Zimmerman,1987) , (American Psychiatric Association, 1987) (Posenthal,etal.2000). (كما وجد كل من ميدفيدوفا (990dovedova)

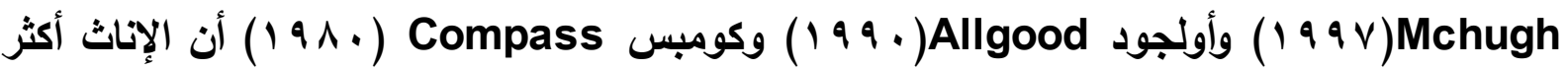
قثقا، وأكثر تعرضا للضغوط. ودراسة Zsuzsa Toth (2011)، التى أثبتث عدم وجود فروق فى القلق بين طلاب اللغة فى الفصل الدراسى الأول وأقرانهم الأكثر خبرة. وكذلك دراسة François Pichette (2009 )، حيث أشارث نتائج الدراسة إلى إنه لا يوجد فروق بين أوجه القّق فى حالتى الدراسة فى الفصل الدراسى أو عن بعد. أما من الدراسات العربية : دراسة أمل الأحمد ( ( . ب)، التى أشارت نتائجها إلى عدم وجود تأثير دال لمتغيرى الجنس والتخصص العلمى فى كل من سمة القلق وحالة القلق مع إرتقاع مستوى القلق لاى أفراد العينة بشكل عام ولاسيما لدى الإناث. وعليه يتضح من الجدول السابق أن قيمة "ت" غير دالة إحصائياً مما يشير إلى أنه لا يوجد فرق دال إحصائياً بين متوسطى درجات الأكور والإناث على مقياس قلق تعلم اللغة الإنجليزية.

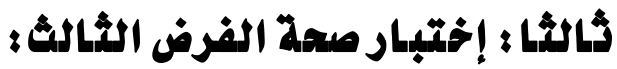
لإختبار صحة الفرض الثالث والأى ينص على أنه "يمكن التببؤ بدرجات قلق تعلم اللغة الإنجليزية لدى تلاميذ المرحلة الإبتدائية من درجاتهم فى مقياس الإنتباه." إستخدمت الباحثة أسلوب 
تحليل الإنحدار Regression analysis بواسطة الحزمة الإحصائية للعلوم الإجتماعية المعروفة الإنة إختصاراً بSpSs. V22 ، ويوضتح جدول (r)، (ع) نتائج هذا الفرض:

جدول (r)

نتائج تحليل الإنحدار للتببؤ بلرجات قلق تعلم اللغة الإنجليزية من درجاتهم فى مقياس الإنتباه

\begin{tabular}{|c|c|c|c|c|c|}
\hline الدلالة & (4) & المربعات & الحرية & المربعات & تباين \\
\hline & & $11 \leqslant$ & & 115 & لل للإنحدار \\
\hline & & $\varepsilon$ & & Vr. & عن الإنحدار \\
\hline & & & & הזs & \\
\hline
\end{tabular}

جدول (\&)

ملخص نتائج تحليل الإنحدار للتبؤ بلرجات قلق تعلم اللغة الإنجليزية من درجاتهم فى مقياس

الإنتباه

\begin{tabular}{|c|c|c|c|c|c|}
\hline متوى الدلالة & قيمة "ت" & بيتا & |المعيارى للمعامل البائى & $\begin{array}{c}\text { المعامل البائى } \\
\text { B }\end{array}$ & المتغير \\
\hline..+1 & 19.1 & - & 1.0 & I.V.z & الثابت \\
\hline. .1 & 0.1 &. .21 &. .17 & . . & الإنتباه \\
\hline
\end{tabular}

مما سبق يتضح صحة الفرض الثالث، حيث ثتفق نتائج هذا الفرض مع نتائج البحوث النفسية إلى الدور الهام الأى يشكله مستوى القلق فى الأداء العقلى والإنجاز، حيث تبين أن كلا من القلق المرتفع، والقلث المنخفض يعتبر من المعوقات التى تعوق الطلاب عن الإنجاز وتحقيق الأهداف، فالقّث المرتفع يشل قدرة صاحبه عن التفكير والحركة والأداء ككل ويؤدى القلق المنخفض إلى ضعف الدافعية والإهتمام واللامبالاة، أما القلق المتوسط فيعد من الطاقات الدافعة للعمل والأداء والإنجاز (زهران، . . . . ). فمستوى القلق عندما يكون معدوما أو منخفض يؤدى إلى تثبيط الأداء ويضعفه حيث لا تتوفز الطاقة الدافعة اللازمة، وعندما يكون مستوى القلق معتدلا أو متوسطا فإنه يعد دافعا الأداء الجيد(وجدان الكحيمى، 1 ( • r). وعندما يكون مفرطا فى الشدة فإنه يكون معوقا للأداء لترتبه على آثار عكسية تتمثل فى إضطراب التفكير وتدهوره، تشتيت الإنتباه وقلة التركيز

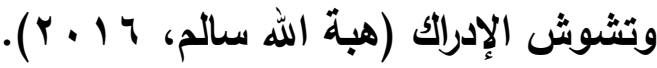
ومن جهة أخرى يمكن تفسير التتائج فى ضوء الإطار النظرى والدراسات السابقة، حيث أثبتت معظم الدراسات السابقة - فى حدود علم الباحثة - مثل دراسة (لبنى جليد، ه ه . . م) أنه يمكن تحديد مستوى تركيز الإنتباه لاى عينة الدراسة فى ضوء الدرجات التى حصلوا عليها جراء أدائهم 


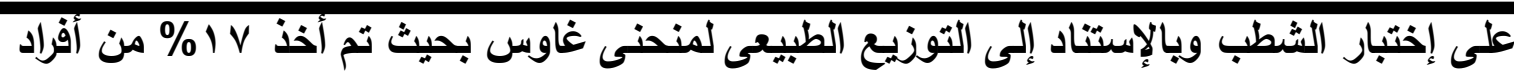

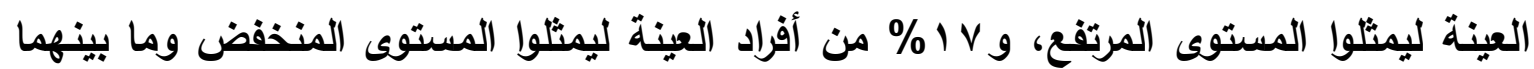
ليمثلوا المستوى المتوسط. يتضح من الجدولين السابقين ما يلى: أن قيمة " ف" وقيمة " ت " المحسوية دالة إحصائياً عند مستوى ال ... مما يثير إلى إمكانية

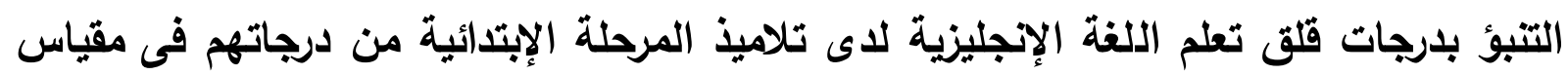
الإنتباه. وتبدو هذه النتيجة منطقية ومتسقة مع نتائج هذه الدراسة التى تم تفسيرها على أساس أن التلاميذ يبذلون جها أكبر فى إستذكار دروسهم؛ وذلك لتحقيق ذاتهم والإستفادة من أوقات الفراغ لديهر.

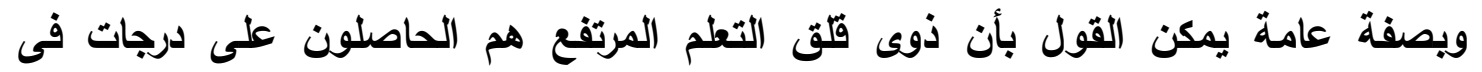

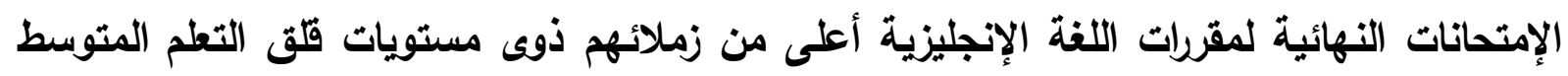
والمنذفض.

\section{توصيات الدراسة ؛}

أوضحت نتائج الدراسة أن هناك تلاميذ يعانون من إرتفاع مستوى قلق تطم اللغة الإنجليزية

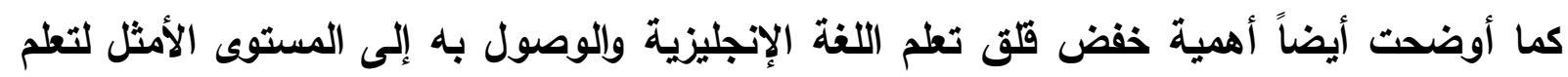

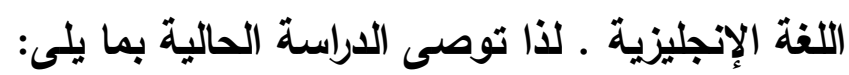

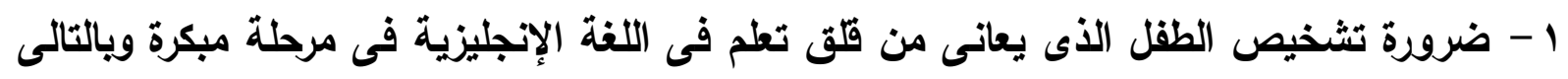
تقديم العلاج المناسب.

r - ضرورة تصميم برامج تدريبية وعلاجية لذوى قلق التطلم فى المواد الدراسية المختلفة.

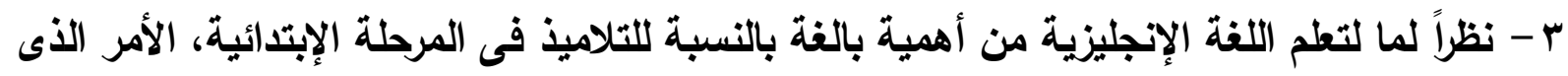

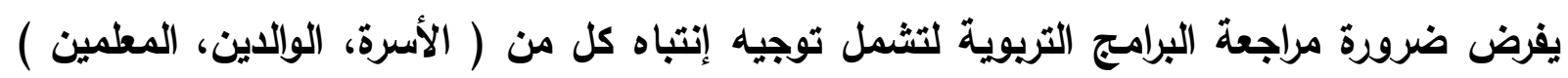

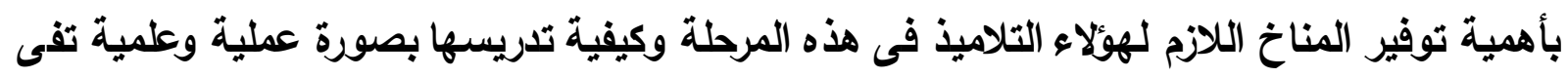
بالغرض منها. צ - إستخدام إستراتيجيات اللفة الإنجليزية لتلاميذ المرحلة الإبتدائية وإختيار المطلمين الأكثر كفاءة لتدريس هذه الإستراتيجيات حتى تكون الإستفادة منها أعم وأشمل.

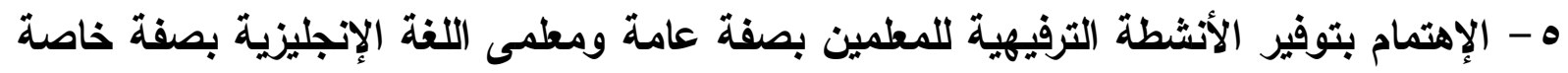

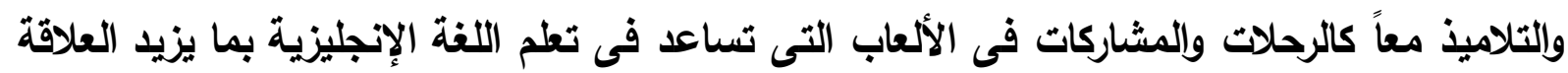
الحسنة بين المعلم وتلاميذه. 


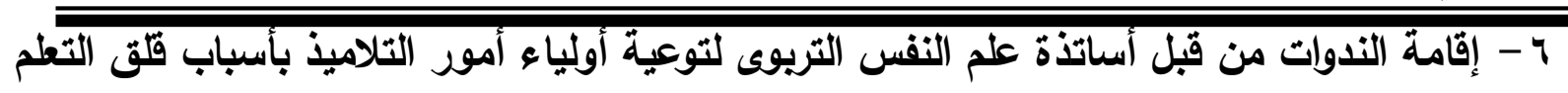

وأعراضها وأساليب التعامل معها.

V - توثيق الصلة بين المدرسة والأسرة للتعرف على القلق الأى يمكن أن يواجهه التلاميذ والعمل على تقديم المساعدة المطلوية لإزالة أو تخفيف النتائج السلبية التى قد يسببها قلق تعلم اللغة الإنجليزية . 1 - تلريب الطلاب على التحدث باللغة الإنجليزية بإستخدام معامل اللغة وذلك للتخفيف من مخاوفهم

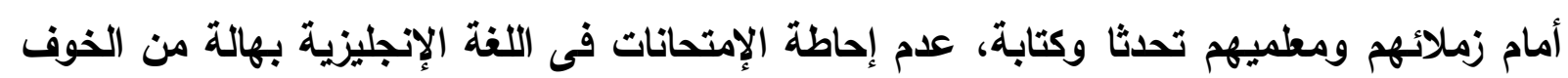
والتوتر حتى لا يزداد مستوى قلق التعلم التعويقى لاى الطلاب، مساعدة المعلم لطلابه فى بناء الثقة بالذات عند تعم اللغة الإنجليزية .

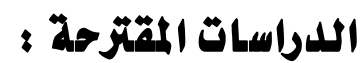

ا - دراسة عن تأثير قلق تعلم اللغة الإنجليزية على التحصيل الدراسى فى مراحل التعليم الإبتدائى حيث إتضح للباحثة خلال الإطار النظرى أن قلق تعم اللغة الإنجليزية يظهر تأثيره بصورة أكبر فى المرحلة الثانوية والجامعية. r - دراسة عن العوامل النفسية المؤثرة فى تعلم اللغة الإنجليزية لدى تلاميذ المرحلة الإبتدائية. 


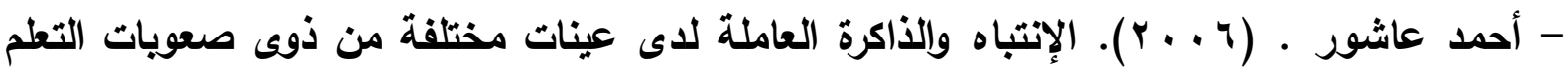
وذوى فرط النشاط الزائد والعاديين. جامعة بنها. كلية التربية.

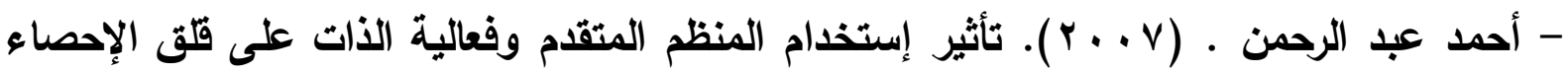

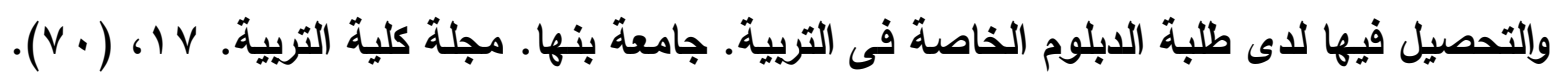
- أحمد عكاشة ـ ( 991 ( ). الطب النفسى المعاصر ـ القاهرة ـ مكتبة الأنجلو المصرية.

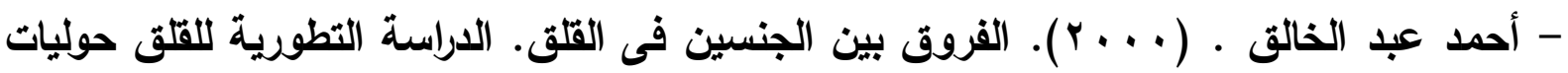

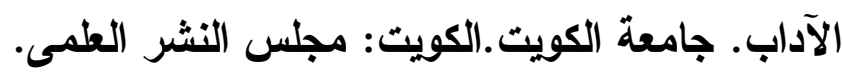
- أحمد عبد الخالق، عبد الفتاح دويدار . (ب9 جو 1). علم النفس أصوله ومبادئه. الإسكندرية. دار

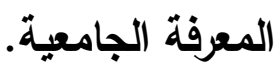

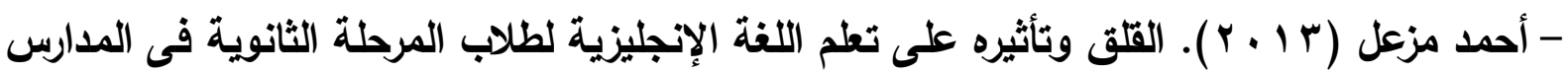
العربية. مجلة جامعة المدينة العالمية لطوم اللغة. ماليزيل العيا.

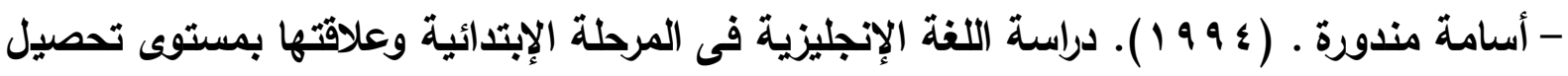
تلاميذ الصف الأول المتوسط فى مقر اللفة الإنجليزية ـ رسالة ماجستير.

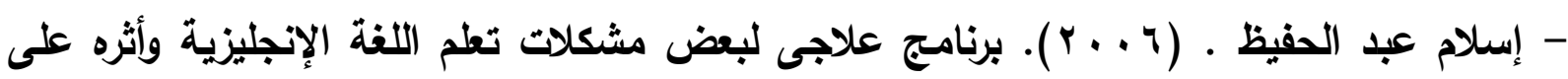

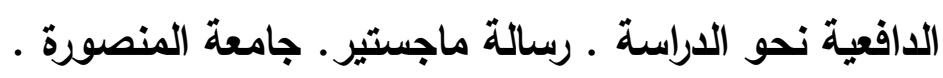

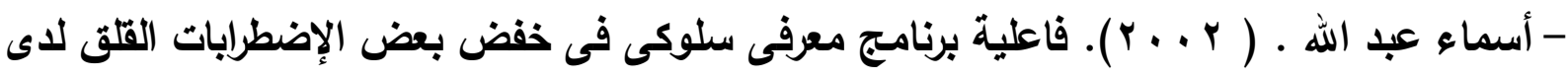

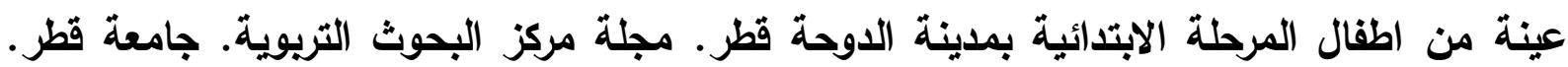

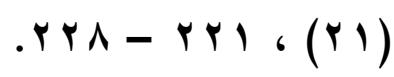

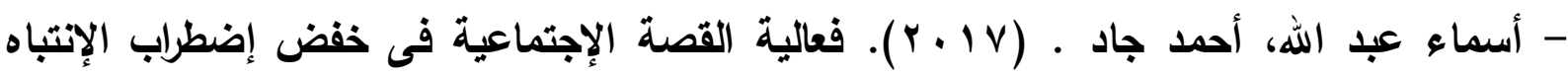

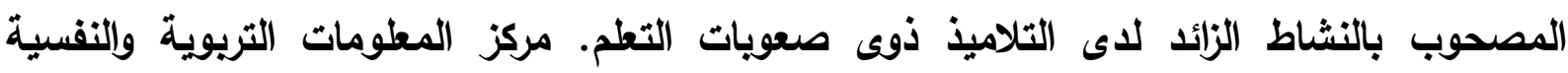
والبيئية. مجلة التربية الخاصة.

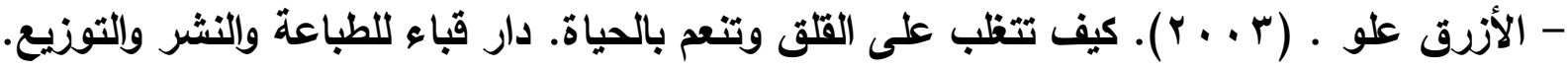
القاهرة. - السيد الفضالى، ميمى السيد ـ ( 1 ـ ؟ ). الإنتباه المتمركز حول الذات وتقدير الذات فى ضوء كل من التخصص والمستوى الاراسى لاى طالبات جامعة الملك خالد. مجلة كلية التربية. جامعة بنها.

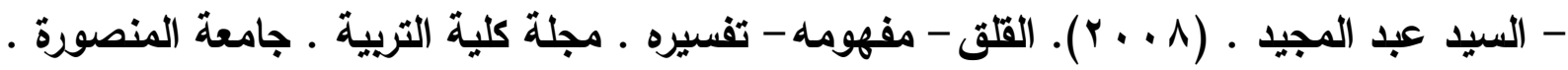
.$(7 \Lambda) 6$ 


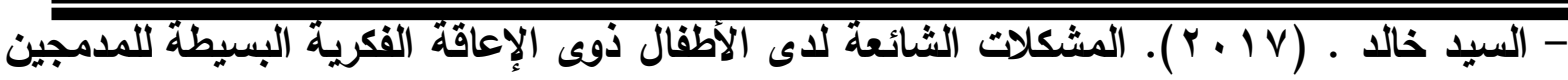
جزئيا والأطفال غير المدمجين من غير ذوى الإعاقة فى كل من السلوك العدوانى وتثتت الإنتباه والشعور بقلق التعلم. مركز المطلومات التربوية والتفسية والبيئية. مجلة التربية الخاصة.

- السيد على، فائقة بلر • (999 (9 ام). إضطراب الإنتباه لاى الأطفال أسبابه وتشخيصه وعلاجه. القاهرة : توزيع مكتبة النهضة المصرية. - الطاهر مجاهدى، مصباح جلاب .(0 ( ب ). بناء مقياس تشخيص التلاميذ ذوى صعويات التعلم النمائية. مجلة الدراسات والبحوث الإجتماعية - جامعة الشهيد حمة لخضر - الوادى .الجزائر.( ( I). $.1 \leqslant 0-1 \times 4$

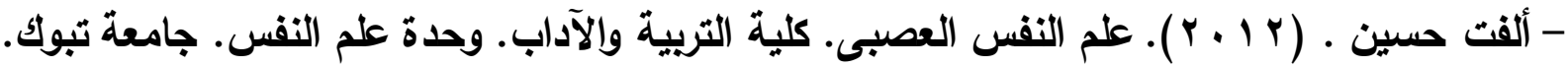
المملكة العربية السعودية: مكتبة الأنجلو المصرية. - إمطانيوس ميخائيل • (r . . . ). دراسة لمقياس القلق وصفة حالة وسمة على عينات من طلبة

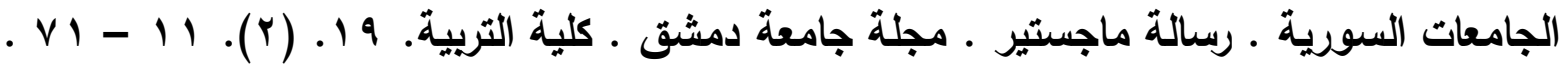
- إنتصار إبراهيم . (ع . . r). قلق تعلم اللغة الإنجليزية وأثره على التحصيل الدراسى لاى تلاميذ المرحلة الإبتدائية. رسالة ماجستير (غير منشورة ). جامعة الإسكندرية.

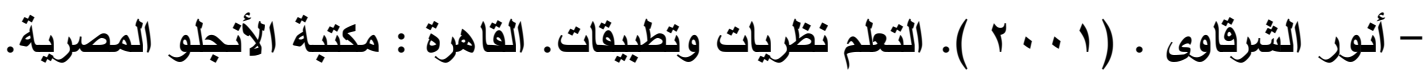

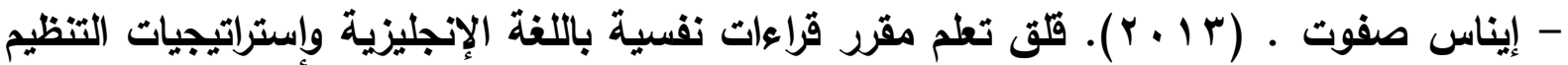
الدراسى لدى طالبات قسم علم النفس بكلية التربية. مجلة الدراسات التريوية والإنسانية. جامعة دمنهور. كلية التربية. - بلر الأنصارى • ( ( . . ). القلق لاى الشباب فى الوطن العربى. قسم علم النفس. كلية العلوم الإجتماعية . جامعة الكويت. - بسماء ادم • (9 . . r). آثز سمتى القلق والغضب على عمليات الأكرة ( التذكر، الإسترجاع،

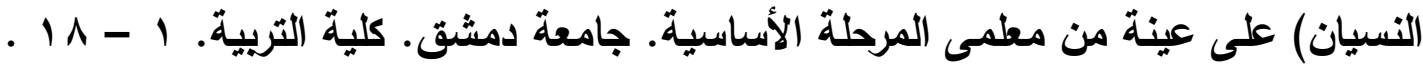

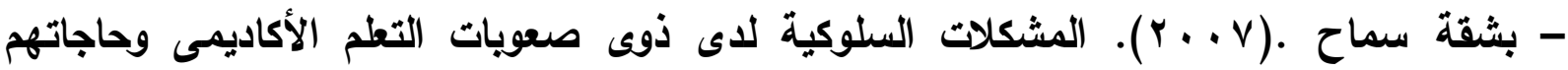
الإرشادية دراسة ميدانية على تلاميذ التعليم الابتدائى. رسالة ماجستير. كلية الاداب. جامعة الحاج

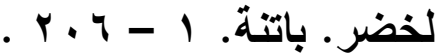
- على أبو غرارة ـ (9 9 ( 1 ). مقياس القلق فى فصول تعلم اللغة الإنجليزية. مجلة جامعة الملك عبد

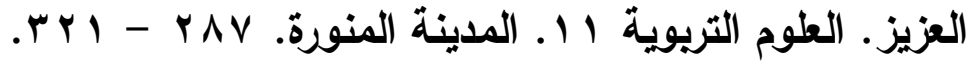




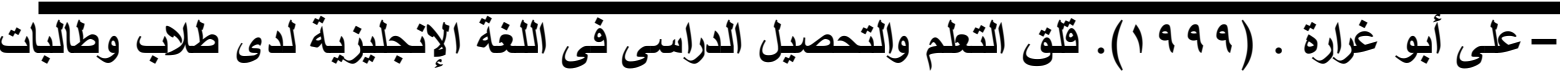
المرحلتين الثانوية والجامعة بالمدينة المنورة. مجلة جامعة الملك عبد العزيز. العلوم التربوية r ا I.

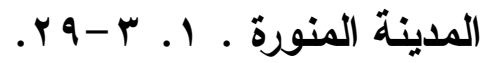

- على مرعى. ( • ( • ). فعالية برنامج لخفض قلق اللغة الإنجليزية لذوى صعويات تعلمها من تلاميذ

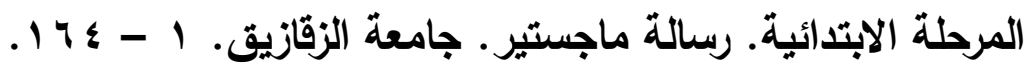
- لبنى جديد. (ه . . ץ). الإنتباه والتحصيل الاراسى ودراسة العلاقة بين مستويات تركيز الإنتباه ومستويات التحصيل الاراسى لدى تلاميذ الصف الخامس الإبتدائى. كلية التربية. جامعة دمشق. مجلة

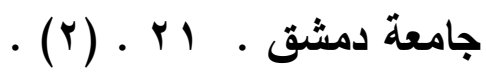

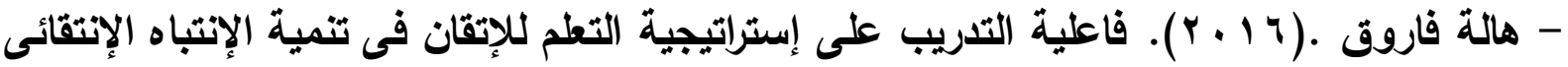
لاى التلميذات القابلات للتعلم ذوات الإعاقة الفكرية. رسالة التربية وعلم النفس. جامعة الملك سعود. الجمعية السعودية للعلوم التربوية والنفسية.

- وائل مسعود .(r l • r). الأساليب التى يستخدمها المعلمون لزيادة دافعية وإنتباه التلاميذ ذوى الإعاقة الفكرية نحو التعم. المجلة التريوية الاولية المتخصصة. المجموعة الدولية للإستشارات والتدريب.

- Abdel - Majeed, M. (2000). The Keyword Method. Apowerful memory aid to vocabulary learning in the EFL classroom. The R.E.C. journal. 17,927.

- Aiping Zhao . (2009). Foreign Language Reading Anxiety. Investigating English-Speaking University Students Learning Chinese As A Foreign Language In The United States. for the degree of Doctor of Philosophy. Spring. Semester. Florida State University. Gollege of Education.

- Alessia Occhipinti . (2009). Foreign Language Anxiety in Class Speaking Activities. Two Learning Contexts in Comparison. AThesis Presented to The Department of Literature. Area Studies and European Languages. The University of Oslo .

- Djigunović \& Jelena . (2006). Language anxiety and language processing. Volume 6. Number 1. 191-212.

- Kun-huei Wu (2010).The Relationship between Language Learners Anxiety and Learning Strategy in the CLT Classrooms. Wu Department of English . Aletheia University 32 Chen-Li St.. Tamsui, Taipei. Taiwan. .3.1. -Sandra Anselmo. (1981). Children hear and remember. Early Childhood Education Journal . 9. 2. 27-28.

- Stephen Monsell \& Jon Driver. ( 2000). Control of Cognitive Processes. 122. 698. ISBN 0262133679. 01. 2005.

- Zaved Ahmed Khan. (2010).The Effects of Anxiety on Cognitive Processing in English Language Learning . VIT University. India. 3. 2. 
- Zsuzsa 1oth. (20II). Forelgn Language Anxiety and Advanced EFL

Learners. AN Interview Study. WoPaLP. 5. Pazmany Peter Catholic University . Piliscsaba . 